\title{
Research on Mechanisms and Control Measures of Surrounding Rock Disaster in Large Section Roadway with Top Coal under the Influence of Tectonic Stress
}

\author{
Yang Yu $₫,{ }^{1}$ Jianfei Lu $₫$, ${ }^{1}$ Dingchao Chen, ${ }^{2}$ Yuxin Pan, ${ }^{1}$ Xiangqian Zhao, ${ }^{2}$ and Cheng Chen ${ }^{1}$ \\ ${ }^{1}$ School of Civil Engineering, Xuzhou University of Technology, Xuzhou 221111, Jiangsu, China \\ ${ }^{2}$ School of Mines, China University of Mining \& Technology, Xuzhou 221116, Jiangsu, China \\ Correspondence should be addressed to Jianfei Lu; 20180702121@xzit.edu.cn
}

Received 9 August 2021; Accepted 26 October 2021; Published 17 November 2021

Academic Editor: Shan Gao

Copyright (C) 2021 Yang Yu et al. This is an open access article distributed under the Creative Commons Attribution License, which permits unrestricted use, distribution, and reproduction in any medium, provided the original work is properly cited.

Based on the research background of large section roadway with top coal (LSRTC) in thick coal seam mining in Wangzhuang Coal Mine, Shanxi Province, China, catastrophe characteristics of the surrounding rock of the LSRTC were investigated and summarized. Based on the principle of damage mechanics, the critical size discriminant of the LSRTC was deduced, and the induction mechanism of section size effect and tectonic stress effect on the roadway surrounding rock disaster was revealed. Accordingly, the roadway surrounding rock control principle with the basic idea of "stabilizing and controlling top coal, reconstructing the coal wall, and limiting floor heave" was put forward, and the roadway surrounding rock stability control countermeasures with the core technology of "strong pressure support for roof + grouting reinforcement for two sides + bolt barrier for floor angle" were developed, which solved the surrounding rock control problem of the LSRTC under the action of tectonic stress and provided a useful reference for the difficult problem of roadway surrounding rock control under similar conditions.

\section{Introduction}

Energy and resource security is an important strategic factor to ensure national economic development and social stability $[1,2]$. In recent years, China's coal production has developed in the direction of intensive and efficient, and the focus of coal mining has gradually shifted to the West. By the end of 2020, the coal output in the West has reached 2.33 billion tons, accounting for $59.7 \%$ of the country. Thick coal seam is a typical occurrence feature of coal resources in Western China. Large mining height comprehensive mechanized mining leads to roof suspension and collapse of the working face, which makes the problems of strong ground pressure appearance and surrounding rock control very prominent, and seriously affects the safety production of the mine $[3,4]$. At the same time, with the large-scale equipment of comprehensive mechanized mining face and the significant improvement of mining intensity and output, the roadway section is required to be larger and larger to ensure normal transportation and ventilation for pedestrians. When the large section roadway of the thick coal seam is excavated along the floor, the top coal is left above. This kind of roadway is called large section roadway with top coal (LSRTC). At present, the width of the mining roadway in some large mines has reached $6.0 \mathrm{~m}$, and the cross-sectional area has reached $25 \mathrm{~m}^{2}$; the open cut span is more than $10 \mathrm{~m}$, and the cross-sectional area is more than $50 \mathrm{~m}^{2}$. In the field engineering practice, the stress state of the surrounding rock of the LSRTC is deteriorated, and the difficulty of control is significantly increased.

There are two characteristics of large section roadway. First, the roadway span is large, the roof is easy to bend and sink, and the surrounding rock control technology is more difficult; secondly, the roof strength of thick seam roadway is weaker than that of rock roadway. When affected by engineering disturbances such as excavation and mining, a large number of cracks are easy to form in the coal body, and the roof stability is greatly weakened. At present, the 
research on the surrounding rock catastrophe mechanism and control technology of the LSRTC suitable for large mining height comprehensive mechanized mining is still in the development stage. Roof falling, wall caving, and floor heave accidents occur from time to time, which is the key problem restricting the popularization and application of this technology. To solve the above problems, scholars have carried out many useful attempts, and many research results have been achieved. The combined support theory is put forward. The core idea of the theory is as follows: the surrounding rock control of large section roadway should be fully combined with the actual geological conditions of the mine, abandon the concept of only improving the support stiffness, realize the combination of rigid and flexible, flexible and stable support, make full use of the bearing capacity of surrounding rock, and maximize the integrity and stability of roadway surrounding rock. Large section roadway support has been developed from simple bolt support to combined support. Combined support technologies such as bolt shotcrete mesh support and bolt cable+ grouting have been successfully applied in various mine engineering practices, which have advantageously promoted the development of roadway excavation technology and support technology [5-15]. However, due to the differences in coal storage and production technical conditions, for the support problem of large section roadway under specific geological conditions, it is mainly determined by field monitoring, theoretical analysis, and numerical simulation, which has not formed a unified understanding; there are still the following problems to be solved: (1) the critical size definition of the LSRTC; (2) the boundary of the LSRTC tension and shear failure and the difference in small section roadway; (3) the catastrophic mechanism of slope and roof fall accidents of the LSRTC caused by the change of roadway size and surrounding rock stress environment; (4) general adaptability of the above problems to be studied under different geological conditions. Therefore, aiming at the above problems, the research methods of restriction investigation, theoretical calculation, numerical simulation, and industrial test were adopted comprehensively. Firstly, the engineering site was investigated, the geological conditions and surrounding rock properties of the LSRTC in Wangzhuang Coal Mine, Shanxi Province, China, were collected, and the catastrophe characteristics of the surrounding rock are summarized and analyzed; secondly, the critical size discriminant of the LSRTC was deduced and determined; thirdly, the section size effect and tectonic stress effect were put forward, the surrounding rock catastrophe mechanism of the LSRTC was revealed, and the targeted control countermeasures and technologies were developed; finally, an industrial test was carried out to analyze the control effect of the LSRTC surrounding rock.

\section{Catastrophe Characteristics and Critical Size Definition of the LSRTC}

2.1. Catastrophe Characteristics of the LSRTC. The stress redistribution of surrounding rock caused by roadway excavation leads to surrounding rock deformation. The failure forms of roadway surrounding rock are diverse, and the failure mechanism is different in different parts and deformation stages of the surrounding rock. For the LSRTC, due to the large span, the small strength of surrounding rock, the deformation, and fracture range are large. Through field investigation, the general characteristics of surrounding rock disaster of the LSRTC are summarized.

(1) Roof subsidence and layer separation are large. The roof of the LSRTC is a composite roof with coal and rock, which is easy to shear failure under the action of concentrated stress caused by excavation. Each layer moves horizontally along the failure structural plane and produces a longitudinal bending displacement at the same time. The separation amount of each layer of the composite roof with coal and rock is directly proportional to the fourth power of the roadway width and is the largest in the middle of the roadway roof [16]. Therefore, for the LSRTC, the roof separation and subsidence increase sharply, and the damage degree of surrounding rock increases significantly.

(2) The failure of roadway surrounding rock is accidental. In the geological structure area, such as small faults, intersections, fracture zone, joint fissure development, or coal seam spacing becoming smaller, due to the large span and composite roof instability, the roadway roof fall is sudden, and the roof fall range is large. The width of roof fall is generally less than the roadway width, and the height of roof fall is generally 1-3 times of the roadway height [17]. In this process, serious wall caving accidents often occur.

(3) The floor heavy is strong. Because the focus of roadway support is on the roof and two sides, and the floor treatment is often regarded, the roadway is prone to extrusion fluidity and floor heave under the action of structural and mining stress. For the LSRTC, the amount of floor heave will increase sharply, and the workload of floor heave treatment is large, and the effect is poor.

In addition, due to the influence of weathering and hydration on the surrounding rock, the roadway will also produce other deformation and failure forms. Due to the large section area of the LSRTC, the deformation and failure degree of the surrounding rock are more serious.

2.2. Critical Size Definition of the LSRTC. According to the disaster characteristics of the LSRTC, the roadway roof is easy to separate, and the damage is the most serious in the middle of the roof. When the damage depth of the composite roof exceeds the range of the anchorage zone, the integrity of the anchor is damaged, the bearing body is transformed into a load body, and the support structure bears a large tensile force. Therefore, the entry of the bolt anchor end in the middle roof into the tensile failure zone is taken as the critical size determination basis to determine whether the roadway can be called large section roadway. 
After roadway excavation, the surrounding rock is damaged to varying degrees under the combined action of self-weight and tectonic stress. The stress distribution characteristics of the two sides of the roadway are shown in Figure 1. Under the action of self-weight stress, the shallow surrounding rock of the two sides deforms and breaks and gradually loses its bearing capacity. Previous research results show that the roadway surrounding rock is divided into elastic zone and plastic zone with the position of peak stress as the dividing line $[18,19]$. Therefore, the boundary line of the elastic-plastic zone is taken as the two fixed ends of the damaged rock beam of the roof. At the same time, for the convenience of calculation, the variation curve of the bearing capacity of the coal in the plastic zone is simplified into a linear relationship.

Taking the peak stress position of the two sides of the roadway as the fixed support end of the damaged rock beam of the roof, the mechanical model of the roadway roof is established, as shown in Figure 2. Among them, the thickness of the damaged rock beam of the roadway roof is $h$. Because the damaged rock beam is symmetrical about the roadway axis, the stress conditions of the two fixed support ends are the same. The bending moment is $M$, the vertical force is $F_{y}$, the roadway width is $a$, and the height is $b$. Under the load $q$ of the overlying strata, the subsidence in the middle of the roadway roof is $h \cdot d$. Release any fixed end and replace it with redundant constraints. At this fixed end, the $y$-direction displacement caused by the bending moment $M$ is $\omega_{M}$, the $y$-direction displacement caused by force $F_{y}$ is $\omega_{1}$, the $y$-direction displacement caused by the uniformly distributed load $q$ is $\omega_{2}$, the $y$-direction displacement caused by the linear load $t$ in the left side plastic zone is $\omega_{3}$, and the $y$ direction displacement caused by linear load $t$ in the right side plastic zone is $\omega_{4}$. Since the displacement of the fixed end in the $y$-direction is zero, the deformation coordination equation is obtained, as shown in the following equation:

$$
w_{M}+w_{1}+w_{2}+w_{3}+w_{4}=0 .
$$

According to the force and moment balance equations and boundary conditions, the $y$-direction displacement of the fixed support end of the damaged rock beam under various constraints can be obtained through the differential equation of the straight beam section:

$$
\left.\begin{array}{l}
w_{M}=-\frac{M l^{2}}{2 E I_{n}} \quad w_{1}=\frac{F_{y} l^{3}}{3 E I_{n}} \quad w_{2}=-\frac{q l^{4}}{8 E I_{n}} \\
w_{3}=\frac{3 t l^{4}}{40 E I_{n}}+\frac{t a l^{3}}{24 E I_{n}} \\
w_{4}=\frac{t a^{3} l}{6 E I_{n}}+\frac{11 t a^{2} l^{2}}{12 E I_{n}}+\frac{5 t a l^{3}}{3 E I_{n}}+\frac{121}{120 E I_{n}} t l^{4}
\end{array}\right\},
$$

where $I_{n}$ is the moment of inertia on the neutral axis.
Substituting equation (2) into equation (1), the bending moment $M$ at the fixed end of the damaged rock beam can be obtained from the deformation coordination equation:

$$
M=\frac{\left(4 l^{2} q a+5 l^{3} q+22 l^{3} t+4 t a^{3}+41 l^{2} t a+22 l t a^{2}\right)}{12 l} .
$$

After the roof rock beam is damaged, its bearing capacity decreases. The effective normal stress at any point in the roof damaged rock beam is shown in the following formula:

$$
\bar{\sigma}=\frac{\sigma}{1-D},
$$

where $\bar{\sigma}$ is the effective normal stress; $D$ is the damage parameter; and $\sigma$ is the normal stress of the roof rock beam without damage, where

$$
\sigma=\frac{q}{2 I_{n}} x^{2} y-\frac{q}{I_{n}}\left(\frac{a}{2}+l\right) x y+\frac{M}{I_{n}} y+\frac{t l^{2}}{6 I_{n}} y,
$$

where $x$ is the horizontal distance between any point and the coordinate origin; $y$ is the distance between any point and the neutral axis.

The entry of the anchor end of the bolt in the middle of the roadway roof into the tensile failure zone is used as the critical size determination basis of the large section roadway. The discriminant is shown in the following formula:

$$
\bar{\sigma}_{x=l+a / 2, y=h / 2-l_{0}} \leq \sigma_{t}(1-D) .
$$

Substituting the relation $x=l+a / 2, \quad y=h / 2-l_{0}$ into equation (3), the following can be obtained from discriminant (6):

$$
\left.\begin{array}{l}
\frac{4 t\left(h-2 l_{0}\right) a^{3}+22 t l\left(h-2 l_{0}\right) a^{2}}{2 b h^{3} l}+ \\
\frac{4 q l^{2}\left(h-2 l_{0}\right) a+41 t l^{2}\left(h-2 l_{0}\right) a}{2 b h^{3} l}- \\
\frac{(48 t+10 q) l^{3} l_{0}+h(24 t+5 q) l^{3}}{2 b h^{3} l}
\end{array}\right\} \leq \sigma_{t}(1-D) .
$$

According to continuum damage mechanics, the roadway damage parameter ${ }_{\mathrm{D}}$ can be defined as the ratio of damage area $S$ to the total area $S_{0}$ of the undamaged material. Assuming that the roadway surrounding rock is divided into several micro elements with different defects, the one-dimensional strength of micro elements conforms to Weibull statistical distribution, and the micro element failure conforms to Mises yield criterion, then

$$
D=\frac{S}{S_{0}}=1-\exp ^{-\left(\varepsilon_{1}-\left(\sigma_{3} / 2 E\right) / \varepsilon_{0}\right)^{m}}
$$

where $\varepsilon_{1}$ is the main strain of the roadway roof; $m, \varepsilon_{0}$ are the Weibull distribution parameters, $\sigma_{3}$ is the confining pressure; $E$ is the elastic modulus of rock mass. 


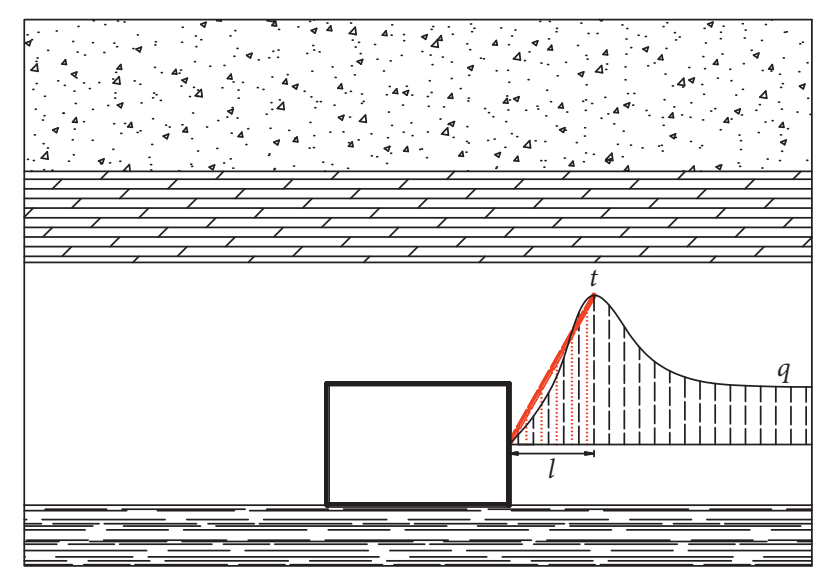

Figure 1: The vertical stress distribution of roadway sides.

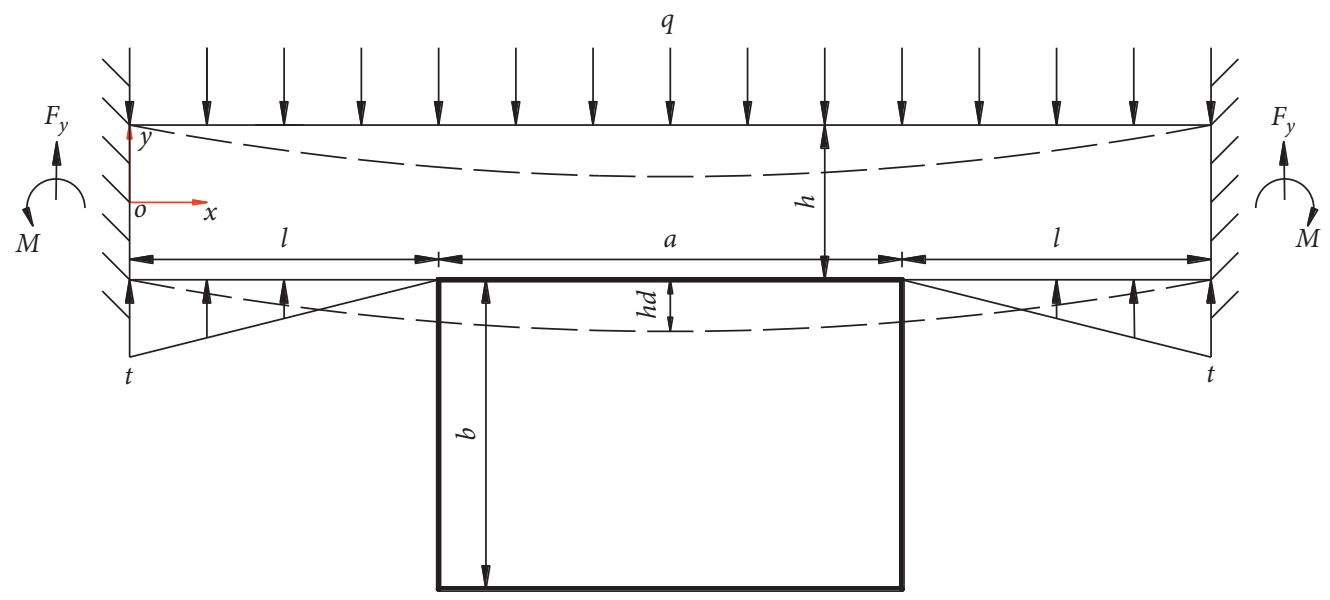

Figure 2: Mechanical model of roadway roof.

Because $\sigma_{3}<a<2 E$, equation (8) can be simplified:

$$
\left\{\begin{array}{l}
D=1-\exp ^{-\left(\varepsilon_{1} / \varepsilon_{0}\right)^{m}}, \\
\varepsilon_{1}=\frac{h_{d}}{h} .
\end{array}\right.
$$

The constitutive relationship between the vertical stress $\sigma_{1}$ and the principal strain $\varepsilon_{2}$ of the two sides is shown in the following equation:

$$
\sigma_{1}=\frac{1}{2} \sigma_{3}+E \varepsilon_{2} .
$$

The relationship between the vertical displacement $z$ of the two sides and the distance $x$ from the surface of the two sides is shown in the following equation:

$$
z=c x^{d}+z_{0}-c l_{s}^{d},
$$

where $L_{S}$ is the distance from the coal wall surface to the original rock stress zone; $z_{0}$ is the vertical displacement under the original rock stress state; $c, d$ are pending parameters.
The axial strain of two sides of the roadway is shown in the following formula:

$$
\varepsilon_{2}=\frac{z}{b}
$$

The relationship between roadway axial strain and confining pressure is shown in the following formula:

$$
\varepsilon_{2}=r e^{-s \sigma_{3}} .
$$

The confining pressure on the surface of the two sides of the roadway is 0 , and the confining pressure in the original rock stress area is restored to $\sigma 0$, and combine equations (10)-(12), and substitute the above conditions into equation (13) to obtain the following equation:

$$
\begin{aligned}
& x=0, \varepsilon_{2}=\frac{z_{0}-c l_{s}^{d}}{h}, \quad \sigma_{3}=0 \\
& \left.\begin{array}{l}
x=l_{s}, \varepsilon_{2}=\frac{z_{0}}{h}, \quad \sigma_{3}=\sigma_{0} \\
\sigma_{0}=\alpha q
\end{array}\right\} .
\end{aligned}
$$


Replace equation (14) with equation (13) to obtain $r$ and $s$. The relationship between axial strain and confining pressure is shown in equation (15), where $x \leq l_{s}$.

$$
\sigma_{3}=\frac{\alpha q}{\ln \left(z_{0}-c l_{s}^{d} / z_{0}\right)} \ln \frac{z_{0}-c l_{s}^{d}}{c x^{d}+z_{0}-c l_{s}^{d}} .
$$

Substitute equation (15) into equation (10) to obtain the stress distribution of two sides of the roadway:

$$
\sigma_{1}=\frac{\alpha q}{2 \ln \left[\left(z_{0}-c l_{s}^{d}\right) / z_{0}\right]} \ln \frac{z_{0}-c l_{s}^{d}}{c x^{d}+z_{0}-c l_{s}^{d}}+E \frac{c x^{d}+z_{0}-c l_{s}^{d}}{h} \text {. }
$$

From the stress distribution curve, the magnitude and position of the peak stress of the two sides can be solved, and the fixed support end of the damaged rock beam of the roadway roof can be determined $l$.

2.3. Case Study. The average buried depth of working face 7105 in Wangzhuang Coal Mine is $450 \mathrm{~m}$, the uniformly distributed load $q$ of overlying strata is $10 \mathrm{MPa}$, the average thickness of mining coal seam is $6.3 \mathrm{~m}$, the elastic model $E$ is 1.0 GPA, and the average horizontal lateral pressure coefficient $\alpha$ is 1.3. The thickness of the top coal and mudstone is $14.75 \mathrm{~m}$, the roadway height is $4.5 \mathrm{~m}$, and the average tensile strength $\sigma_{t}$ is $2.0 \mathrm{MPa}$, the vertical displacement $z_{0}$ of the two sides of coal under the original rock stress state is $0.02 \mathrm{~m}$, the width of the elastic-plastic zone of the two sides is $6.0 \mathrm{~m}$, and the Weibull distribution parameters $m, \varepsilon_{0}$ are 2 and 0.05 , respectively. The parameters $c$ and $d$ of the vertical displacement change curve of the two sides are determined by indoor experiments to be 0.015 and 2, respectively. A group of fractures are developed in the coal seam, with a certain included angle with the roadway, and the fracture spacing is $1.2 \mathrm{~m}$.

Substitute the above parameters into equation (16) to obtain the vertical stress change curve of the roadway wall, as shown in Figure 3. It can be seen from Figure 3 that the peak stress of the coal wall is $24.5 \mathrm{MPa}$, the distance between the peak stress position and the coal wall surface is $5.0 \mathrm{~m}$, the coal body on the roadway surface loses its bearing capacity, and the vertical stress is only $2.8 \mathrm{vMPa}$. The vertical stress of the surrounding rock within $3.0 \mathrm{~m}$ from the coal wall surface is lower than the original rock stress, and the roadway wall is damaged by different degrees.

The influence of top coal thickness and strength on the coal wall stress distribution is shown in Figure 4. It can be seen from Figure 4 that, with the increase of the thickness of top coal, the peak value of coal wall stress continues to increase, and the position of peak stress continues to expand to the deep. The change of top coal strength has little effect on the position of the stress peak but has a great effect on the stress peak.

The effective anchorage length $l_{0}$ of the bolt is $2.1 \mathrm{~m}$, and by substituting the above parameters into equation (7), it is $4.5 \mathrm{~m}$. Therefore, when the roadway width is greater than $4.5 \mathrm{~m}$, tensile failure occurs outside the roadway roof anchorage zone, and it is difficult to maintain the surrounding rock. At this time, the roadway is called large section roadway. The definition of the LSRTC is the premise of carrying out the research on this kind of roadway, which provides an important basis for surrounding rock control of this kind of roadway.

\section{Section Size Effect on Surrounding Rock Disaster of the LSRTC}

By studying the influence law of different roadway width and height on the stability of roadway surrounding rock, the mechanism of surrounding rock catastrophe induced by section size effect is revealed. FLAC3D software is used for numerical simulation. According to the geological report and borehole histogram provided by the project site, the thinner rock strata are combined, and the boundary effect is taken into account. Model size length $\times$ wide $\times$ height $=$ $50 \mathrm{~m} \times 20 \mathrm{~m} \times 50 \mathrm{~m}$, which is divided into 117000 units and 124440 nodes in total. The bottom of the model is fixed, and the four sides restrict the horizontal movement. The selfweight of the overburden is $10 \mathrm{MPa}$ on the upper boundary, and the horizontal lateral pressure coefficient is 1.3. The Mohr-Coulomb yield criterion is used to judge the failure of rock mass. The transport roadway of working face 7105 is excavated along the coal seam floor, and the top coal with the thickness of $1.8 \mathrm{~m}$ is reserved. The mechanical parameters of rock mass are shown in Table 1.

\subsection{Action Mechanism of Roadway Width on Surrounding Rock Catastrophe}

3.1.1. Influence of Roadway Width on Surrounding Rock Deformation. To study the influence of roadway width on the surrounding rock stability, the fixed roadway height is $4.5 \mathrm{~m}$, and seven calculation models with roadway width of $3.5 \mathrm{~m}, 4.0 \mathrm{~m}, 4.5 \mathrm{~m}, 5.0 \mathrm{~m}, 5.5 \mathrm{~m}, 6.0 \mathrm{~m}$, and $6.5 \mathrm{~m}$ are established, respectively. Under the conditions of different roadway widths, the surface deformation law of roadway surrounding rock is shown in Figure 5. It can be seen from Figure 5 that when the roadway width is $3.5 \mathrm{~m}$, the roof subsidence and the two sides displacement are bigger, and the floor heave is small. With the increase of roadway width, the increase of roof subsidence increases. Especially, when the roadway width is greater than $4.5 \mathrm{~m}$, the increase begins to increase sharply. The two sides and floor are less affected by the roadway width, and the increase remains relatively stable.

The influence of roadway width on the internal deformation of surrounding rock is shown in Figure 6. It can be seen from Figure 6 that the roadway width has a great impact on the roof and floor, and a small impact on the two sides. The influence of roadway width on the internal deformation of surrounding rock decreases with the increase of depth. This trend is particularly obvious in the shallow part of the surrounding rock. The deformation of the surrounding rock within $3.0 \mathrm{~m}$ of the roadway surface accounts for $80 \%$ of the total deformation. 


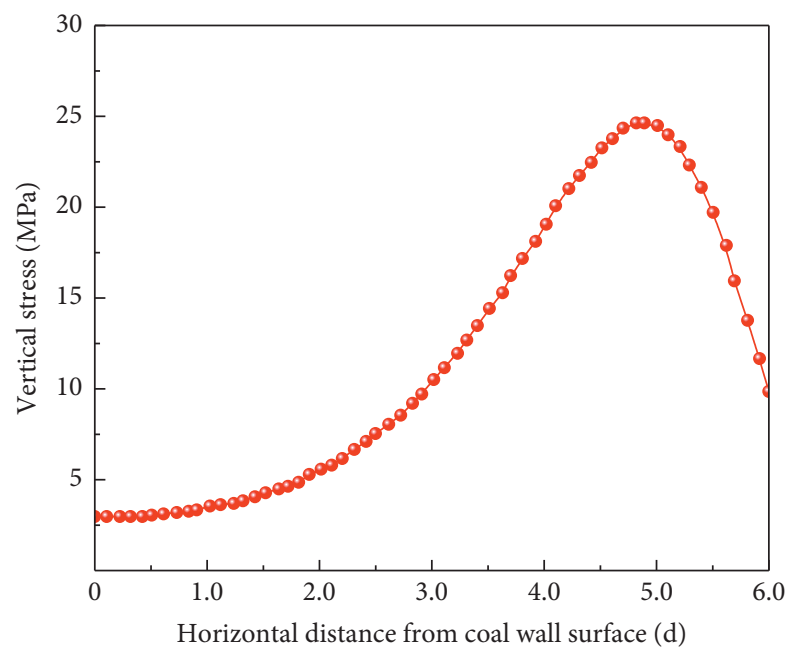

Figure 3: Variation curve of vertical stress in coal wall of roadway.

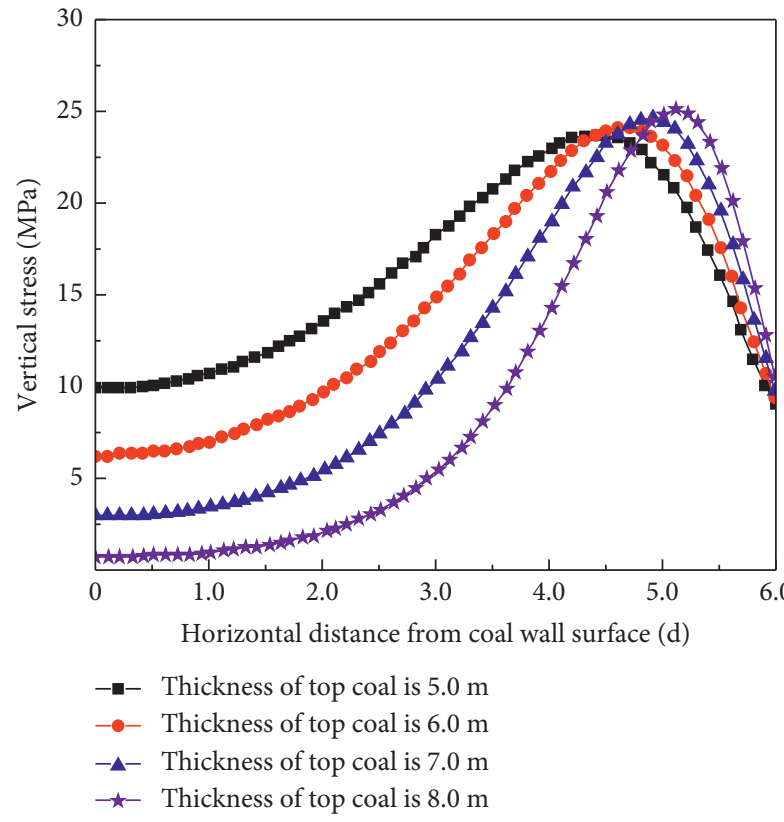

(a)

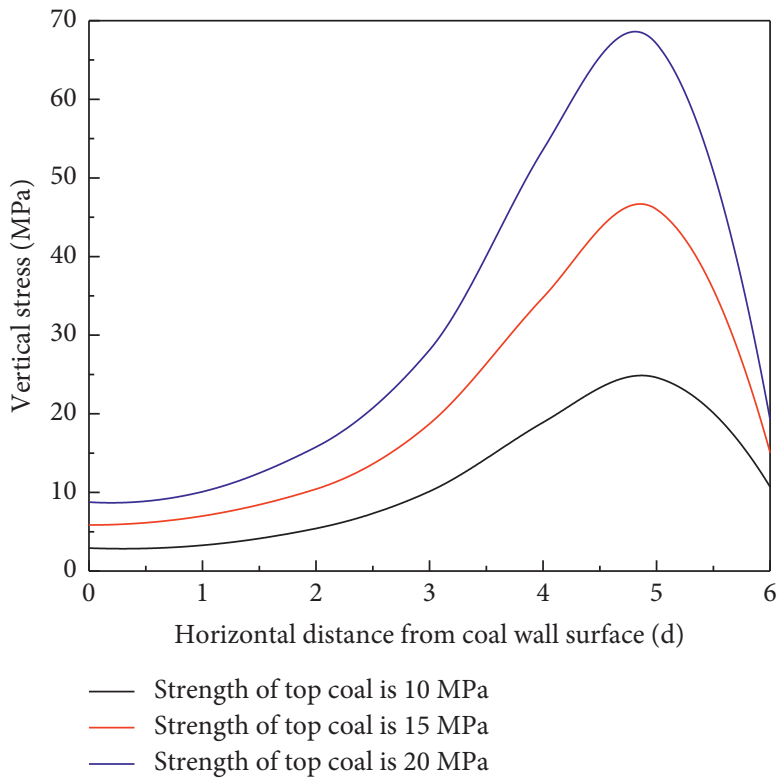

(b)

Figure 4: The influence of top coal thickness and strength on the stress distribution of coal seam. (a) Top coal thickness; (b) top coal strength.

3.1.2. Influence of Roadway Width on Plastic Zone Distribution of Surrounding Rock. The distribution characteristics of the surrounding rock plastic zone under different roadway widths are shown in Figure 7, and the statistical data of roadway roof tensile failure depth and area are shown in Figure 8. It is defined as follows: the stretch width ratio is the ratio of tensile failure width to roadway width. The stretch depth ratio is the ratio of tensile failure depth to total failure depth; the stretch area ratio is the ratio of tensile failure area to total failure area.

It can be seen from Figures 7 and 8 that there is an influence law of roadway width on the plastic distribution of surrounding rock:
(1) Tensile failure occurs in the roof and floor of the roadway and the middle of the two sides, and the shoulder angle of the roadway is mainly shear and tensile failure. The roadway width has a great influence on the distribution of the plastic zone of the surrounding rock. There is an inflection point at $4.5 \mathrm{~m}$, and the expansion speed of the plastic zone before and after the inflection point increases significantly.

(2) The roadway width has a great influence on the tensile failure degree of roof. With the increase of roadway width, the tensile failure width, depth, and area of the roof continue to increase, and the roof 
TABLe 1: Mechanical parameters of rock mass.

\begin{tabular}{|c|c|c|c|c|c|c|}
\hline Lithology & $\begin{array}{c}\text { Elastic modulus } \\
(\mathrm{GPa})\end{array}$ & $\begin{array}{l}\text { Poisson's } \\
\text { ratio }\end{array}$ & $\begin{array}{c}\text { Friction angle } \\
\left({ }^{\circ}\right)\end{array}$ & $\begin{array}{c}\text { Cohesive force } \\
\text { (MPa) }\end{array}$ & $\begin{array}{c}\text { Tensile strength } \\
(\mathrm{MPa})\end{array}$ & $\begin{array}{l}\text { Thickness } \\
\text { (m) }\end{array}$ \\
\hline Overlying strata & 3.1 & 0.32 & 25.0 & 22.0 & 2.8 & 10.00 \\
\hline Fine sandstone & 3.2 & 0.24 & 26.7 & 20.0 & 4.8 & 4.50 \\
\hline Mudstone & 1.9 & 0.28 & 18.0 & 3.2 & 2.0 & 10.75 \\
\hline $\begin{array}{l}\text { Mudstone and sandy } \\
\text { mudstone }\end{array}$ & 1.9 & 0.28 & 18.8 & 3.6 & 2.6 & 2.20 \\
\hline Coal & 1.0 & 0.30 & 17.0 & 2.0 & 1.2 & 6.30 \\
\hline Mudstone & 1.9 & 0.28 & 18.0 & 3.2 & 2.0 & 4.25 \\
\hline Fine sandstone & 3.2 & 0.24 & 26.7 & 20.0 & 4.8 & 2.00 \\
\hline Overburden strata & 3.5 & 0.22 & 24.5 & 18.5 & 3.6 & 10.00 \\
\hline
\end{tabular}

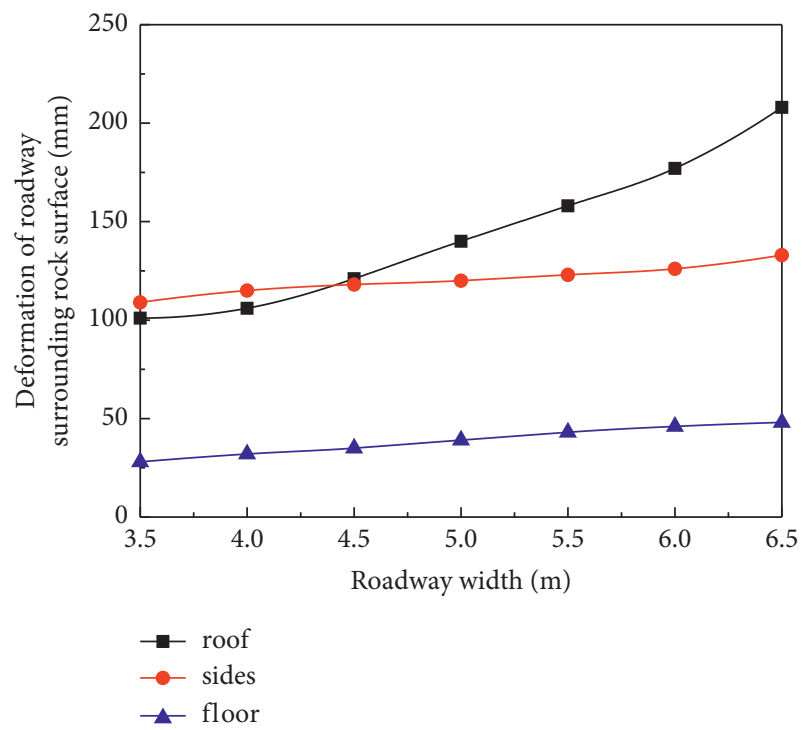

FIGURE 5: Influence of roadway width on surface deformation of surrounding rock.

stretch width ratio, the stretch depth ratio, and stretch area ratio also increase rapidly. The roadway width is more than $5.0 \mathrm{~m}$, the tensile failure depth of the roof has exceeded the anchorage length of the bolt, and the stability of the roof has decreased sharply. The increase of roadway width changes the roof failure mode. The roof failure of small section roadway is mainly shear failure, and the roof failure of large section roadway is mainly tensile failure.

3.1.3. Influence of Roadway Width on Surrounding Rock Stress. The variation law of vertical and horizontal stress of roadway surrounding rock is shown in Figure 9. It can be seen from Figure 9 that the vertical stress of the roadway surrounding rock has the following variation rules:

It can be seen from Figure 9 that the horizontal stress of the roadway surrounding rock has the following variation rules:

(1) There are two peaks in the horizontal stress of the roadway roof and floor. The horizontal stress changes a little within $2.0 \mathrm{~m}$ from the roadway surrounding the rock surface, increases greatly outside $2.0 \mathrm{~m}$, reaches the first peak at $4.0 \mathrm{~m}$, then decreases slightly, then continues to rise, reaches the second peak at $6.0 \mathrm{~m}$, and finally decreases slowly and tends to be stable; (2) the increase the range of horizontal stress in the two sides is slow first, then fast, and finally tends to be flat, and the change trend presents the characteristics of "inverse Z-shape"; (3) roadway width has great influence on the horizontal stress of roof and floor, and roadway width has little influence on the horizontal stress of two sides.

\subsection{Action Mechanism of Roadway Height on Surrounding} Rock Catastrophe. To analyze the influence of roadway height on the surrounding rock stability, first fix the roadway width of $5.0 \mathrm{~m}$, and then establish 7 calculation schemes with roadway height of $2.5 \mathrm{~m}, 3.0 \mathrm{~m}, 3.5 \mathrm{~m}, 4.0 \mathrm{~m}, 4.5 \mathrm{~m}, 5.0 \mathrm{~m}$, and $5.5 \mathrm{~m}$, respectively. The analysis method of the action mechanism of roadway height on surrounding rock disaster is consistent with that of roadway width on surrounding rock disaster. Considering the space limitation of the article, this section only describes the conclusions and will not be displayed in graphics.

3.2.1. Influence of Roadway Height on Surrounding Rock Deformation. The roof subsidence and two-side displacement are greatly affected by the roadway height, and the floor heave is less affected by the roadway width; the influence of roadway height on the deep deformation of the surrounding rock gradually decreases with the increase of the distance from the roadway surface, and this decreasing trend is particularly significant within $3.0 \mathrm{~m}$ from the roadway surface, accounting for $80 \%$ of the total deformation of surrounding rock.

The influence of roadway height on the distribution of plastic zone of surrounding rock: (1) tensile failure is mainly found in the roof and floor of roadway and the middle of the two sides, and shear and tensile shear failure are mainly found in the shoulder angle of the roadway; (2) the roadway height has a great influence on the distribution of surrounding rock plastic zone, and a sudden change occurs at $4.5 \mathrm{~m}$. When it is less than $4.5 \mathrm{~m}$, the range of surrounding rock plastic zone increases slowly, and when it is greater than $4.5 \mathrm{~m}$, the range of surrounding rock plastic zone increases rapidly; (3) with the increase of roadway height, the tensile failure height, depth, and area of two sides gradually increase, but the growth rate of stretch depth ratio and stretch area ratio of two sides is slow; (4) with the increase of 

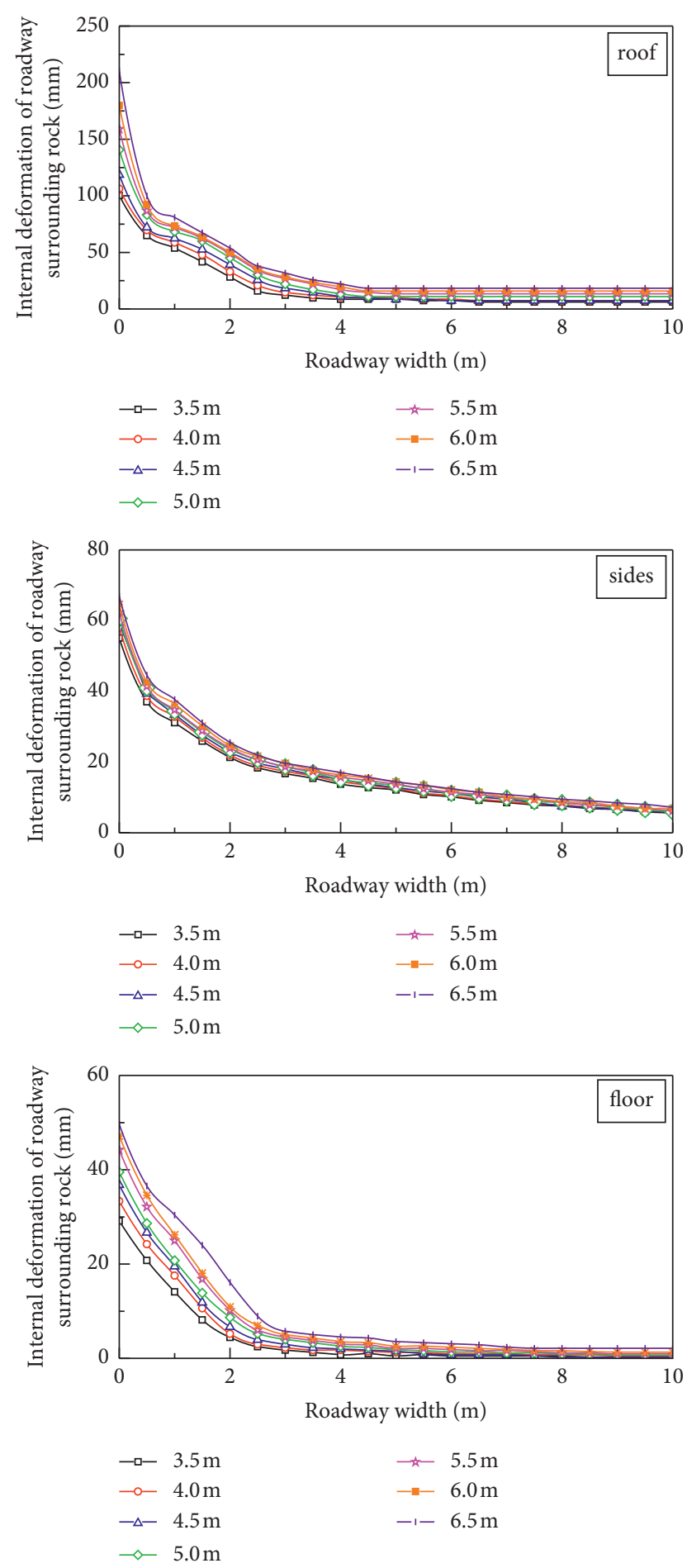

FIGURE 6: Influence of roadway width on internal deformation of surrounding rock.

roadway height, the failure form of two sides changes. When the roadway height is less than $3.0 \mathrm{~m}$, it is mainly shear or tension shear failure, and when the roadway height is greater than $3 \mathrm{~m}$, it is mainly tensile failure.

3.2.2. Influence of Roadway Height on Surrounding Rock Stress. Variation law of vertical stress of roadway surrounding rock: (1) the vertical stress of surrounding rock within $2.0 \mathrm{~m}$ from the roadway surface is less than $1.0 \mathrm{MPa}$. With the distance being away from the roadway surrounding rock surface, the vertical stress gradually increases, and the increasing range of shallow surrounding rock is large, and the increase range of deep surrounding rock is small; (2) the roadway height has a great influence on the vertical stress of the two sides. The greater the roadway height, the more significant the reduction of the stress of the shallow surrounding rock of the two sides; (3) with the distance from the two sides of the roadway, the vertical stress first increases sharply to the peak value and then tends to be stable.

Variation law of horizontal stress of roadway surrounding rock: (1) the horizontal stress of surrounding rock within $2.0 \mathrm{~m}$ from the roadway surface is less than $3.0 \mathrm{MPa}$. The horizontal stress outside $2.0 \mathrm{~m}$ from the roadway surface first increases rapidly to the stress peak, then decreases slightly, then continues to rise to the second peak, then decreases slowly, and tends to be stable; (2) for the surrounding rock at the same depth from the roadway surface, the horizontal stress of the shallow surrounding rock of the roof and floor is inversely proportional to the roadway height, the horizontal stress of the deep surrounding rock of the roof and floor is directly proportional to the roadway height, and the horizontal stress of the surrounding rock of the two sides is inversely proportional to the roadway height; (3) the greater the roadway height, the greater the distribution range of surrounding rock in low stress state. Compared with the roadway width, the influence of roadway height on the horizontal stress of surrounding rock is more obvious.

\section{Tectonic Stress Effect of Surrounding Rock Catastrophe in the LSRTC}

The in situ stress test results show that the maximum principal stress direction of 7105 transportation roadway in Wangzhuang Coal Mine is close to the horizontal one, and the measured lateral pressure coefficient is up to 2.32 , indicating that the tectonic movement has a significant impact on the stability of the roadway surrounding rock [20]. Based on this, a numerical calculation model is established for research. The size, boundary conditions, and failure criteria of the numerical calculation model are the same as those in Section 3. The lateral pressure coefficients of horizontal stress are taken as $1.0,1.3,1.6,1.9,2.2$, and 2.5 , respectively. By studying the influence law of different lateral pressure coefficients on the stability of roadway surrounding rock, the mechanism of surrounding rock catastrophe induced by the tectonic stress effect in LSRTC is revealed. The roadway excavation section is rectangular with wide $\times$ height $=$ $5.0 \mathrm{~m} \times 3.5 \mathrm{~m}$ and buried depth $400 \mathrm{~m}$.

4.1. Deformation Law of Roadway Surrounding Rock. With the increase of roadway surrounding rock depth, the ratio of vertical stress to horizontal stress decreases gradually. The deformation law of the roadway surrounding rock under different lateral pressure coefficients is shown in 

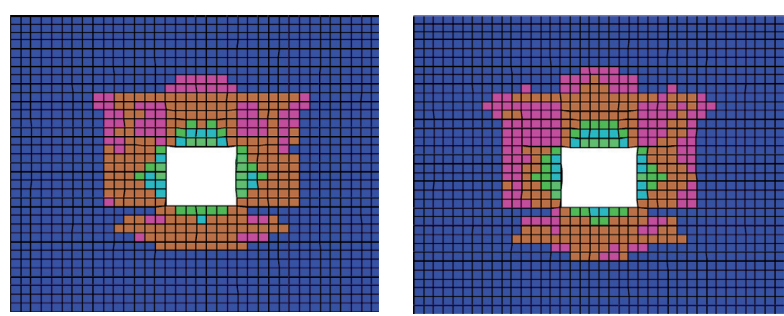

Block State
$\square$ None
$\square$ shear-n shear-p
$\square$ shear-n shear-p tension-p
$\square$ shear-n tension-n shear-p
tension-p
$\square$ shear-p
$\square$ tension-n shear-p tension-p

(a)

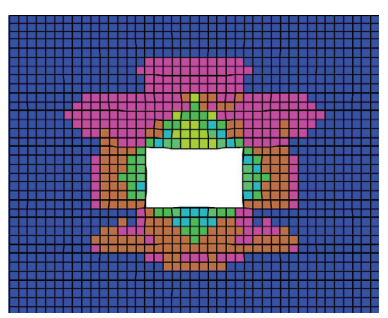

Block State
$\square$ None
$\square$ shear-n shear-p
$\square$ shear-n shear-p tension-p
$\square$ shear-n tension-n shear-p
tension-p
$\square$ shear-p
$\square$ tension-n shear-p tension-p

(e)

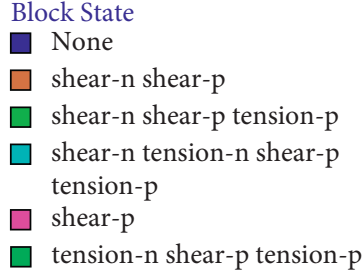

(b)

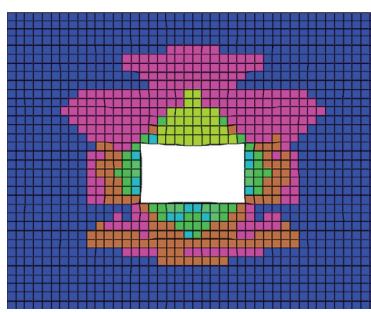

Block State

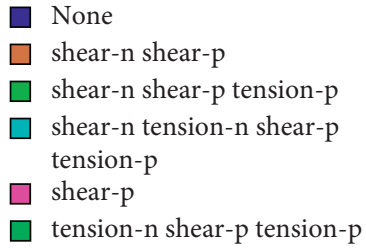

(f)
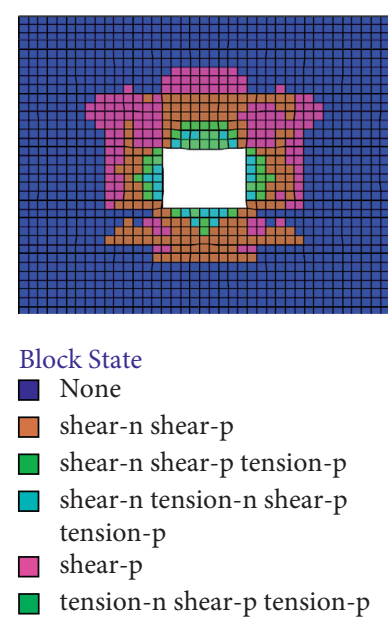

(c)

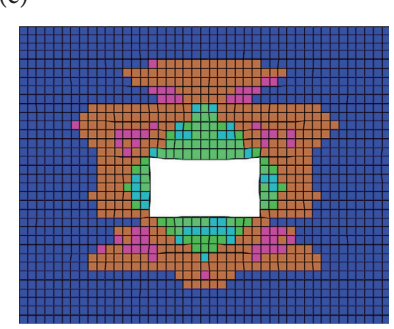

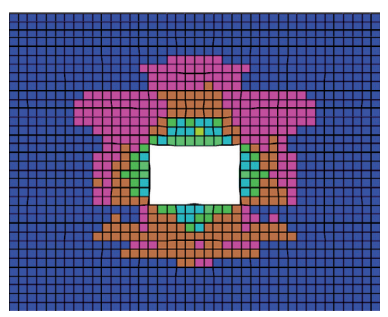

Block State

$\square$ None

$\square$ shear-n shear-p

$\square$ shear-n shear-p tension-p

$\square$ shear-n tension-n shear-p tension-p

$\square$ shear-p

$\square$ tension-n shear-p tension-p

FiguRe 7: Distribution characteristics of plastic zone in surrounding rock of roadway with different width. (a) $3.5 \mathrm{~m}$; (b) $4.0 \mathrm{~m}$; (c) $4.5 \mathrm{~m}$; (d) $5.0 \mathrm{~m}$; (e) $5.5 \mathrm{~m}$; (f) $4.0 \mathrm{~m}$; (g) $4.5 \mathrm{~m}$; (h) legend.

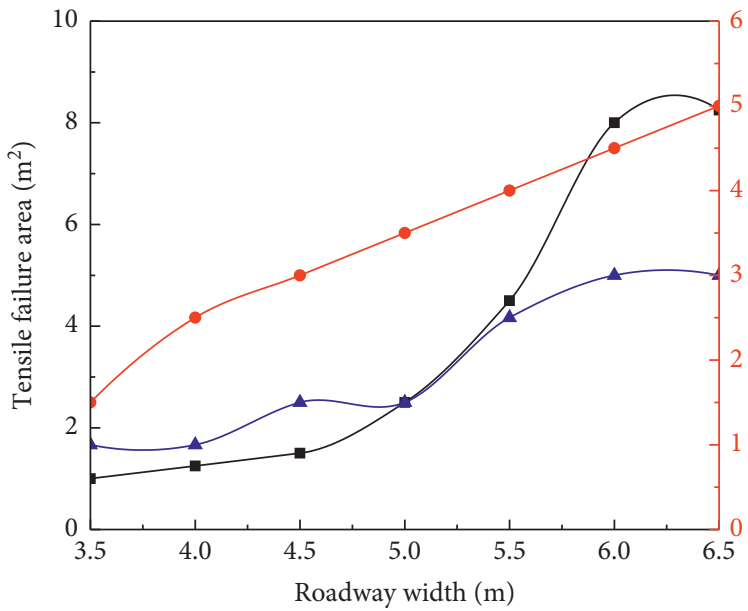

- - damaged area

- $\boldsymbol{-}$ - failure width

- - failure depth

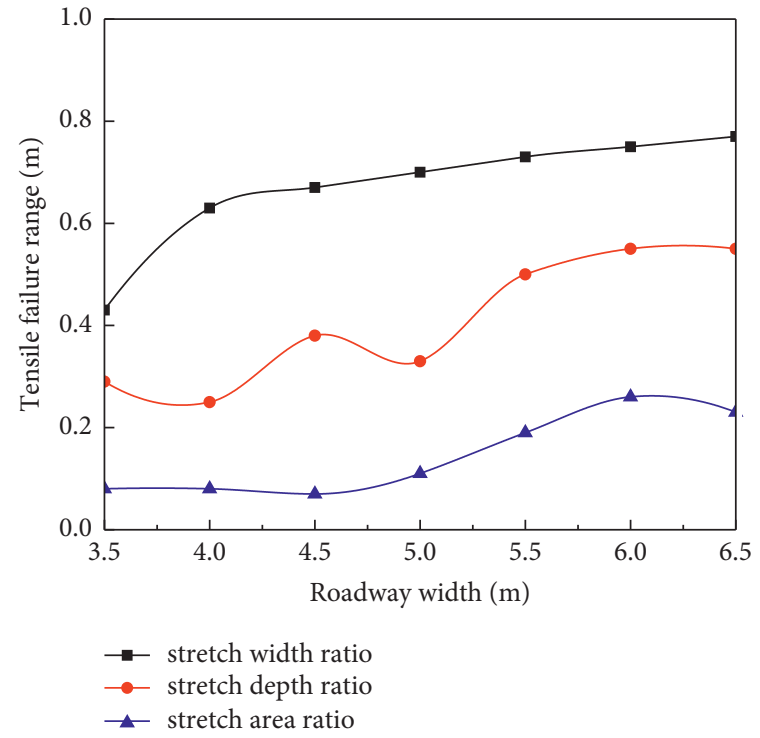

(b)

FIgURE 8: Influence of roadway width on roof damage degree. (a) Absolute value; (b) proportion. 

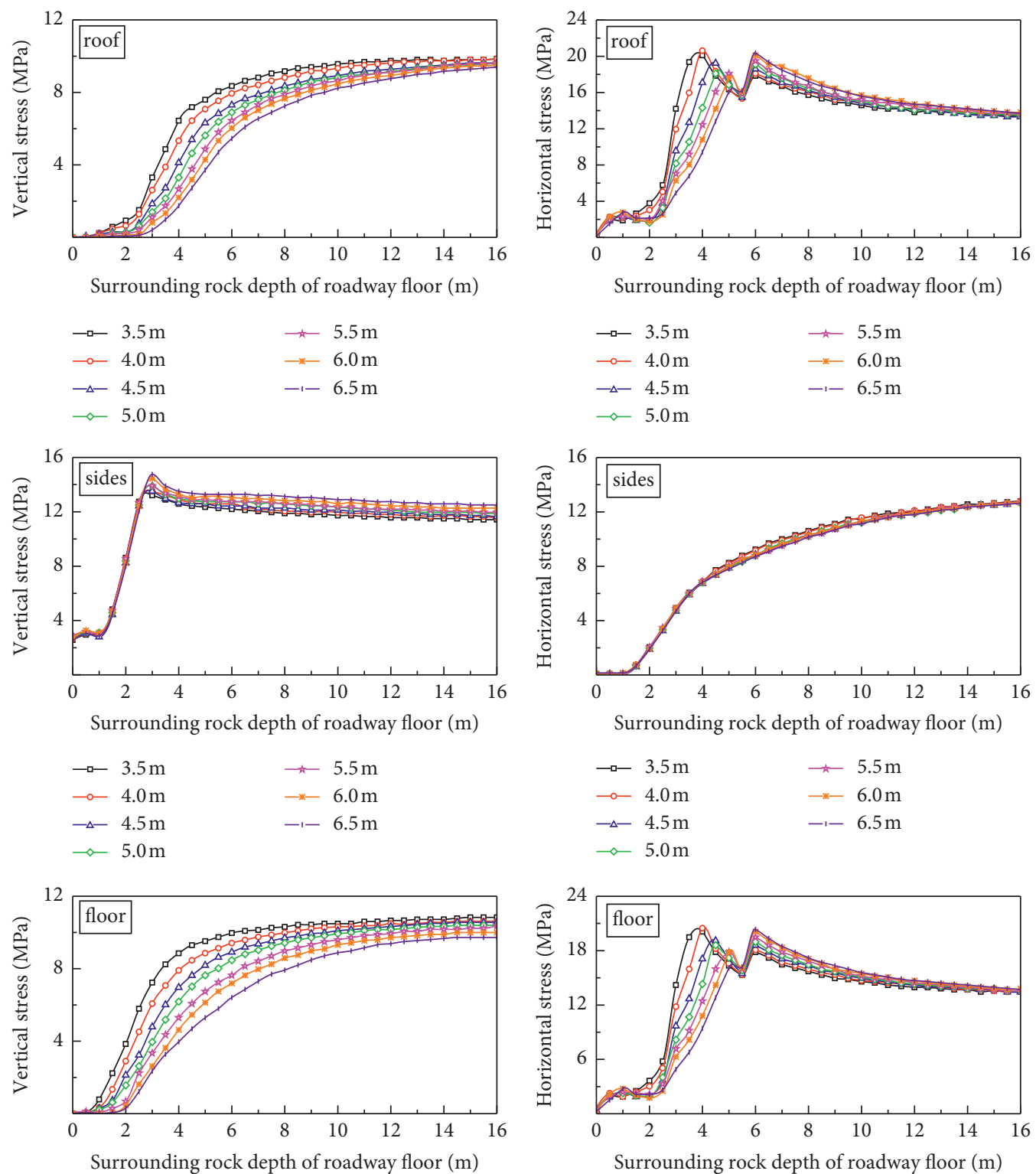

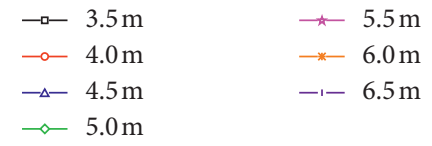

(a)
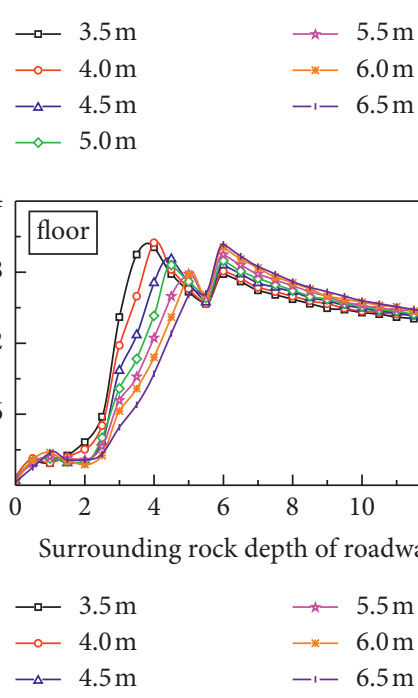

(b)

FIGURE 9: Influence of roadway width on surrounding rock stress. (a) Vertical stress; (b) horizontal stress.

Figure 10. It can be seen from Figure 10 that there is a deformation law of roadway surrounding rock under the influence of tectonic stress.

The vertical displacement of the roadway surrounding rock began to stabilize at the position $4.9 \mathrm{~m}$ from the roof surface and $6.7 \mathrm{~m}$ from the floor surface. With the increase of lateral pressure coefficient, the roof subsidence increases continuously, and the increase range shows a trend from fast to slow; the displacement of the two sides increases significantly, and the increase range remains stable; the increase of pressure borne by the two sides leads to the increase of floor heave. Tectonic stress has a great influence on the roadway roof and relatively little on the two sides and floor.

4.2. Stress Distribution of Roadway Surrounding Rock. The stress distribution characteristics of the roadway surrounding rock are shown in Figure 11. It can be seen from Figure 11 that there are stress distribution characteristics of roadway surrounding rock under the influence of structural stress. 


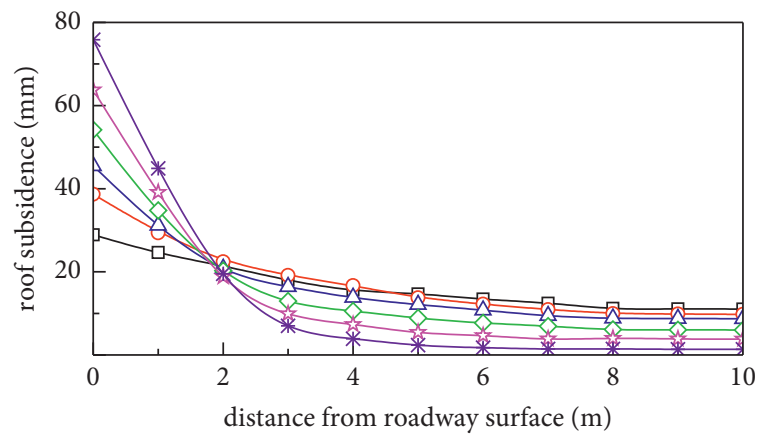

$$
\begin{array}{ll}
-\square-1.0 & -\checkmark 1.9 \\
-\bigcirc-1.3 & -\longleftarrow-2.2 \\
-\triangle-1.6 & -*-2.5
\end{array}
$$

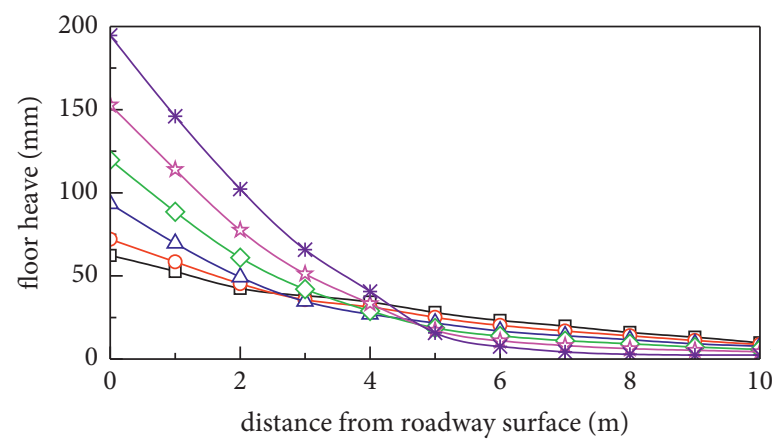

$$
\begin{array}{ll}
-\square-1.0 & \checkmark-1.9 \\
-\bigcirc-1.3 & -\longleftarrow-2.2 \\
-\triangle-1.6 & -*-2.5
\end{array}
$$

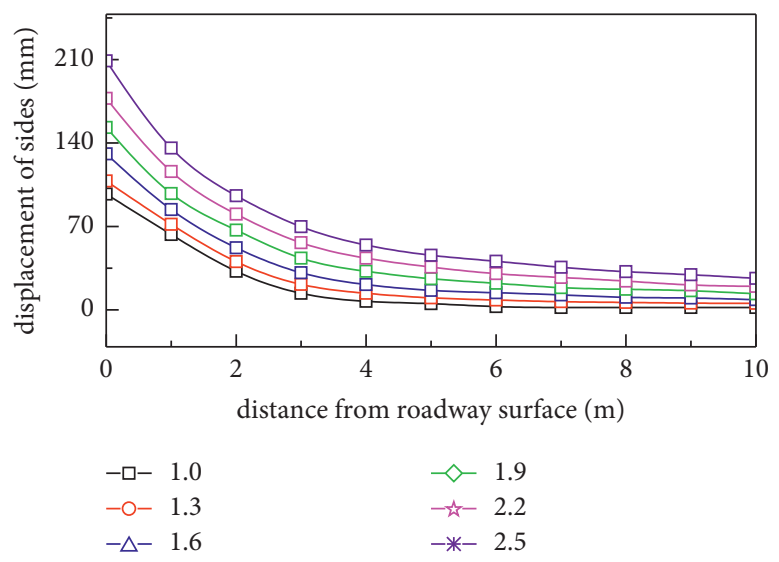

FIGURE 10: Deformation law of roadway surrounding rock.

(1) The vertical stress of the two sides of the roadway first increases and then decreases with the distance away from the roadway surface. The vertical stress is less affected by the lateral pressure coefficient, and the vertical stress curve of the roadway surrounding rock tends to be consistent under different lateral pressure coefficients. The horizontal stress of the two sides of the roadway increases with the distance away from the roadway surface, but the change range is not obvious. The increase range is large within $3.0 \mathrm{~m}$, and the increase range decreases significantly after exceeding $3.0 \mathrm{~m}$.
(2) The vertical stress of the roadway roof and floor increases gradually with the distance away from the roadway surface, but when the lateral pressure coefficient is large, there is a fluctuating trend of "first increasing and then decreasing." The horizontal stress of the roadway roof and floor increases gradually with the distance away from the roadway surface, reaches the peak at $5.0 \mathrm{~m}$, and begins to stabilize at $8.0 \mathrm{~m}$.

4.3. Distribution of Plastic Zone of Roadway Surrounding Rock. Under different lateral pressure coefficients, the 

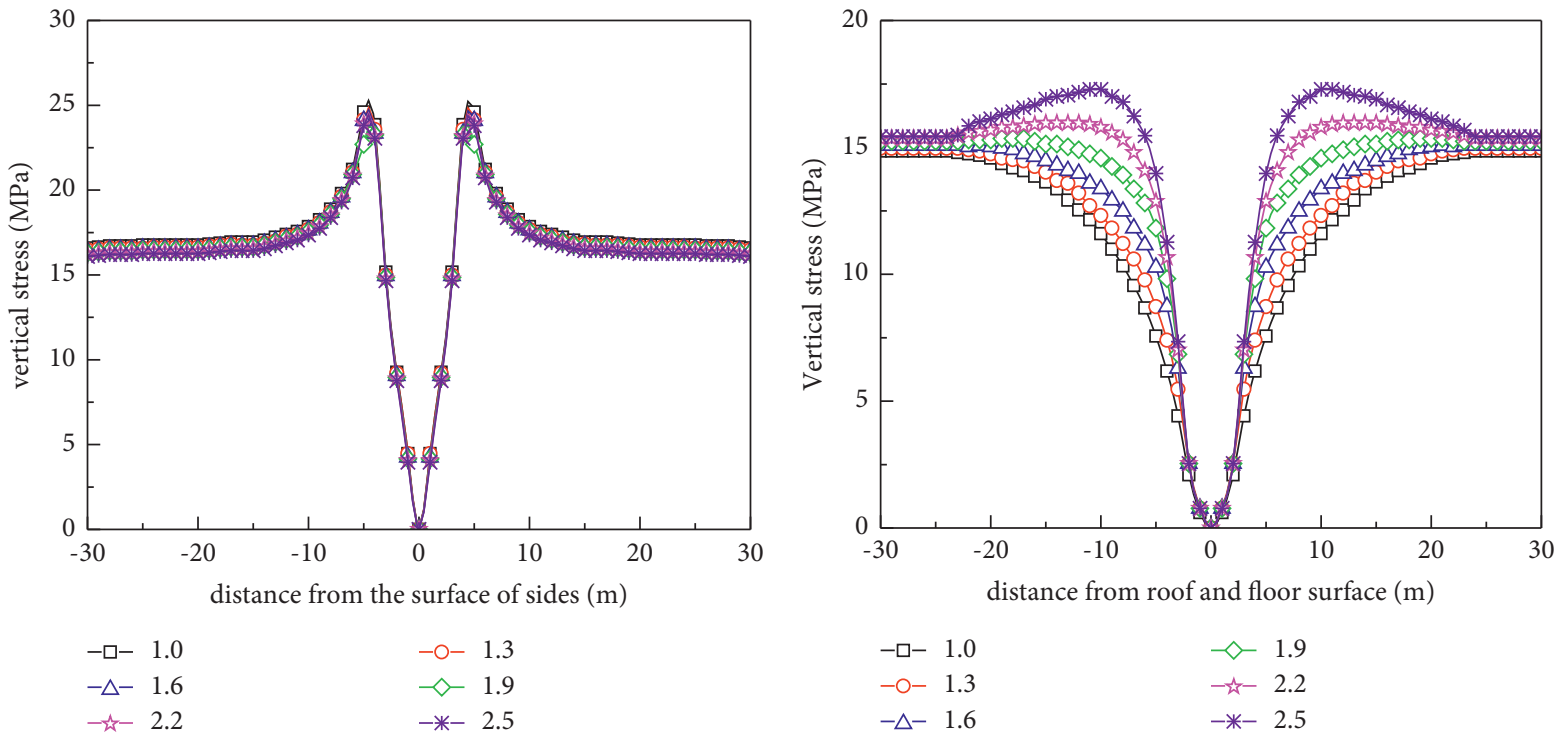

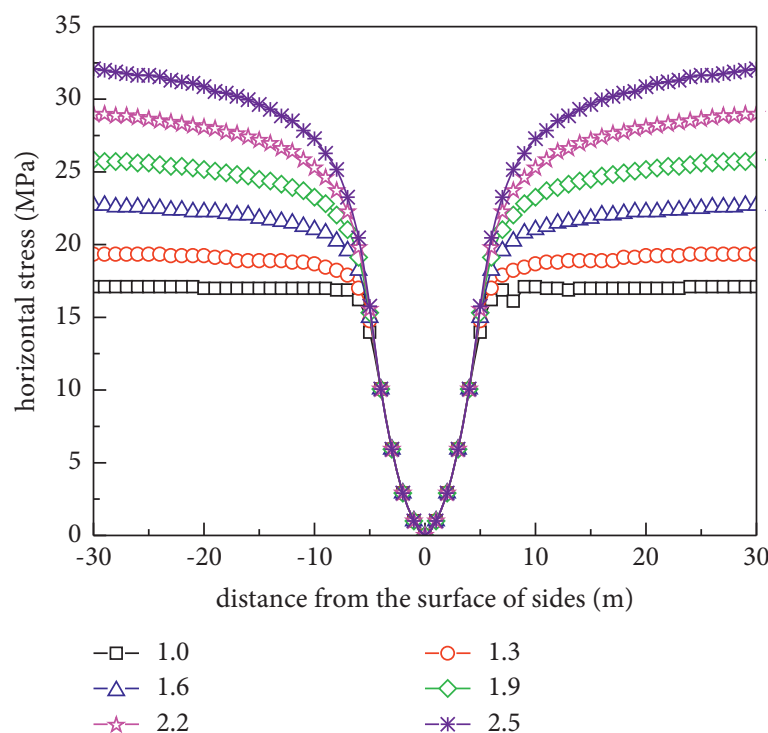

(a)

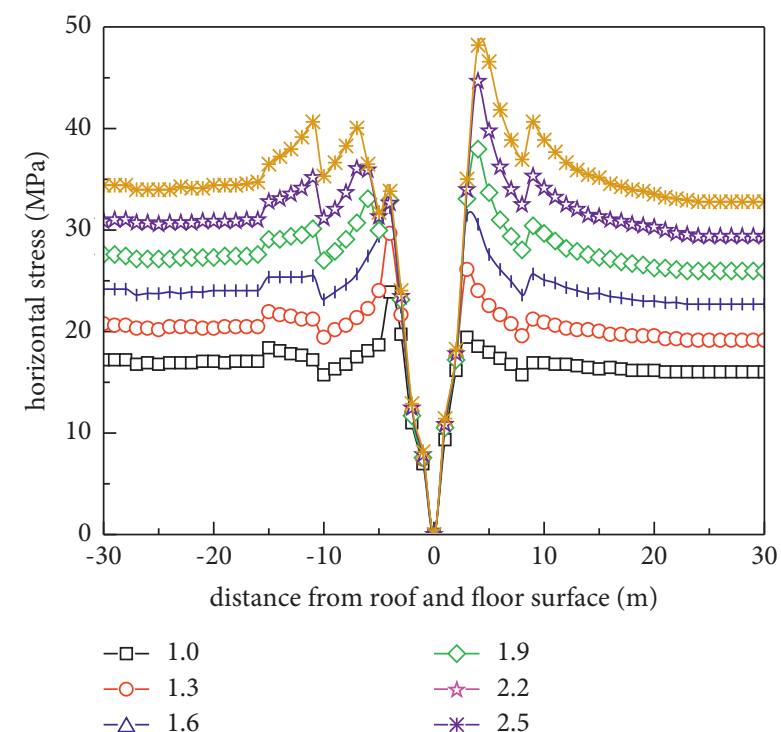

(b)

FIGURE 11: Stress distribution of roadway surrounding rock. (a) Sides; (b) roof and floor.

failure forms of roadway surrounding rock are mainly tensile failure, shear failure, and plastic slip, which is shown in Figure 12. It can be seen from Figure 12 that, with the increase of lateral pressure coefficient, the range of surrounding rock plastic zone continues to expand. When $\lambda<2.2$, the plastic failure depth of roof and floor and two sides increases rapidly. When $\lambda \geq 2.5$, the plastic failure depth of the roof and floor and two sides is stable, and almost no longer expands.

\section{Control Countermeasures of Surrounding Rock in the LSRTC}

5.1. Control Principle. Taking the transportation roadway of 7105 working face in Wangzhuang Coal Mine as the research object, combined with the test results of rock mechanical properties, and based on the surrounding rock catastrophe mechanism of the LSRTC induced by section size effect and tectonic stress effect, we put forward the surrounding rock control principle of the LSRTC based on the basic idea of "stabilizing top coal, reconstructing the coal wall and limiting floor heave." The stability control countermeasures of roadway surrounding rock with the core technology of "strong support roof + grouting reinforcement, two sides + bolt barrier floor corner" are developed. The tensile failure degree of the roadway roof surface is reduced through high-strength and high prestressed anchors to limit the horizontal slip between rock layers. With the help of the prestressed hollow grouting bolt, the shear failure resistance of the two sides of weak coal in the roadway is enhanced, and the control range of the anchor body is expanded. The floor corner bolt is used to block the transfer path of stress and surrounding rock and control the floor heave [21-25]. The self-bearing 


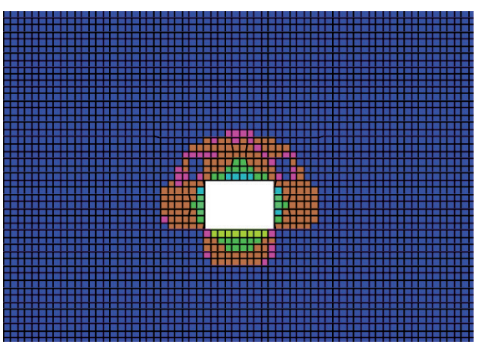

(a)

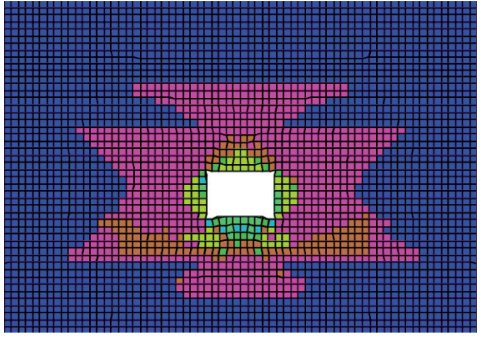

(d)

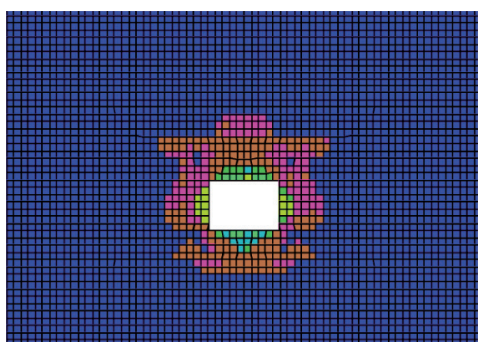

(b)

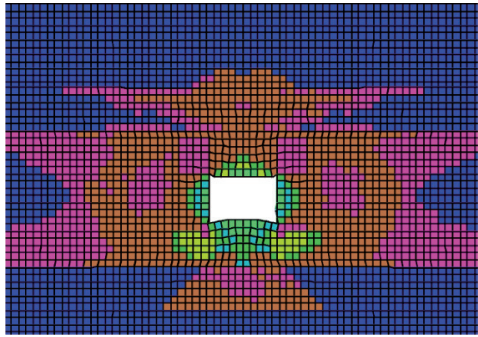

(e)

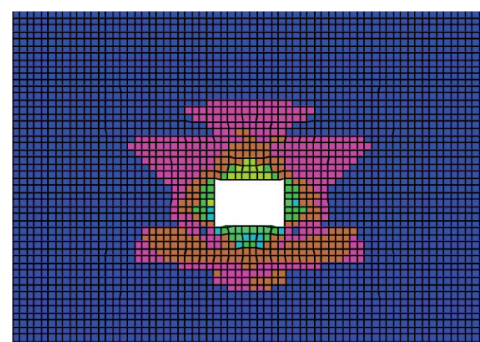

(c)

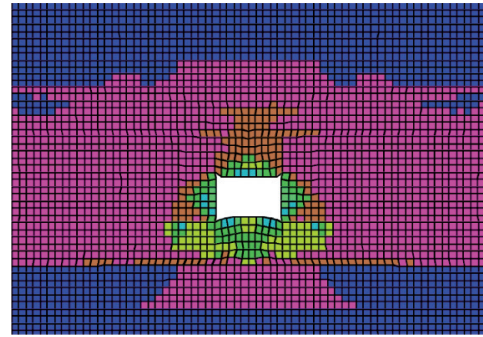

(f)

FiguRE 12: Distribution characteristics of plastic zone of roadway surrounding rock. (a) $\lambda=1.0$; (b) $\lambda=1.3$; (c) $\lambda=1.6$; (d) $\lambda=1.9$; (e) $\lambda=2.2$; (f) $\lambda=2.5$.

capacity of the surrounding rock is gradually rebuilt, and the overall stability of the roadway is ensured. The specific control ideas and countermeasures are shown in Figure 13.

5.2. Implementation Effect. Through theoretical calculation and engineering analogy, the high-strength prestressed bolt with a diameter of $20 \mathrm{~mm}$ and length of $2400 \mathrm{~mm}$ is selected for the roof of the transportation roadway of 7105 working faces, and the row spacing is $850 \mathrm{~mm} \times 900 \mathrm{~mm}$, high-strength prestressed anchor with a diameter of $22 \mathrm{~mm}$ and length of $8300 \mathrm{~mm}$ is selected, and the row spacing is $1500 \mathrm{~mm} \times 1800 \mathrm{~mm}$. Grouting bolt with a diameter of $25 \mathrm{~mm}$ and length of $3000 \mathrm{~mm}$ is selected for the two sides, and the row spacing is $800 \mathrm{~mm} \times 900 \mathrm{~mm}$, and the grouting material is a micro-nano-prestressed composite grouting material. The high-strength prestressed yielding bolt with a diameter of $22 \mathrm{~mm}$ and length of $2800 \mathrm{~mm}$ is selected at the floor corner, and the row spacing is $900 \mathrm{~mm}$. The roadway support section is shown in Figure 14.

In the first 10 days after roadway excavation, the surface displacement increases rapidly, the deformation speed of the roof and floor is $6.6 \mathrm{~mm} / \mathrm{d}$, and the moving speed of the two sides is $7.8 \mathrm{~mm} / \mathrm{d}$. After the rock mass is disturbed by excavation, the energy contained in itself is released in a short time, and the bearing capacity of the surrounding rock is reduced. After the surrounding rock

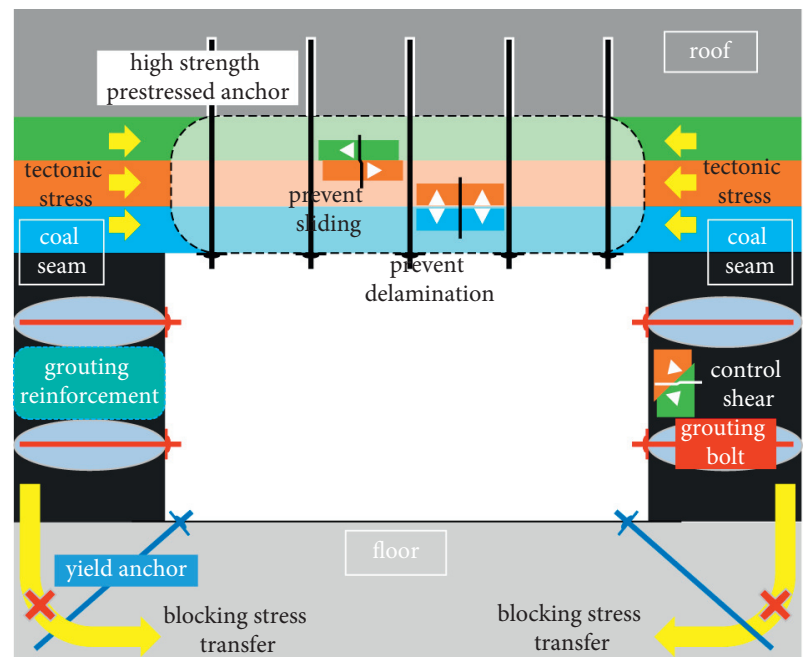

FIgURE 13: The specific control ideas and countermeasures of roadway surrounding rock control.

becomes stable, the deformation speed gradually decreases and becomes stable after 30 days. Finally, the deformation of the roof and floor is $88 \mathrm{~mm}$, and the proximity of the two sides is $96 \mathrm{~mm}$. During the mining of the working face, the support is strengthened with the help of a single hydraulic prop. The roadway section can meet the use requirements, and the overall control effect of the roadway is good, as shown in Figure 15. 


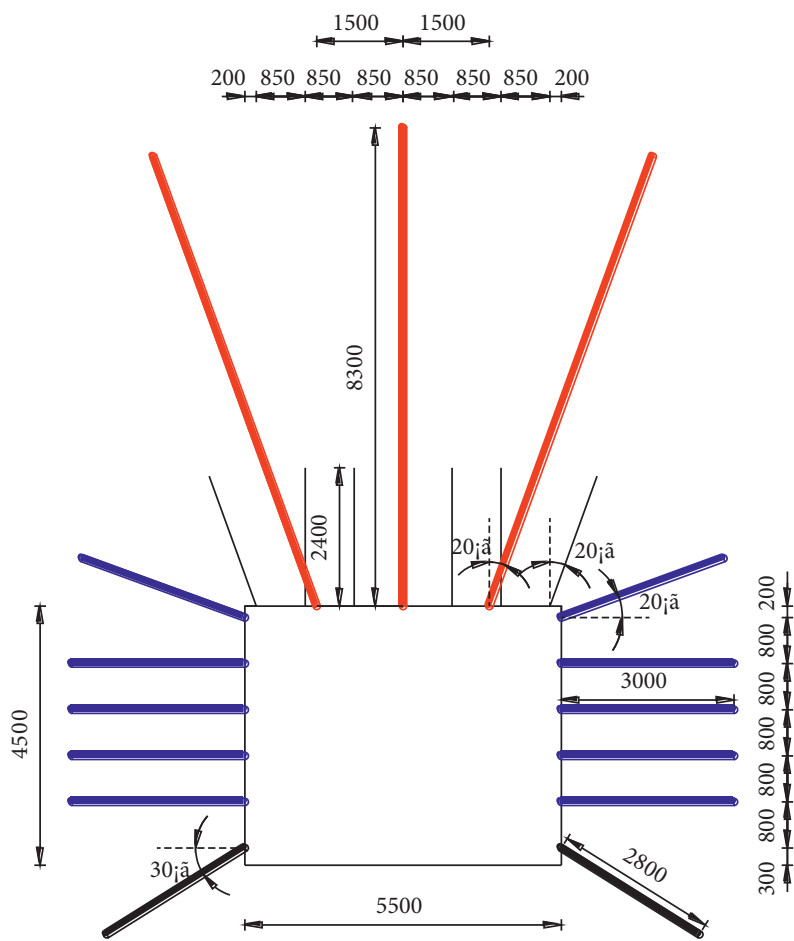

FIGURE 14: Roadway support section.

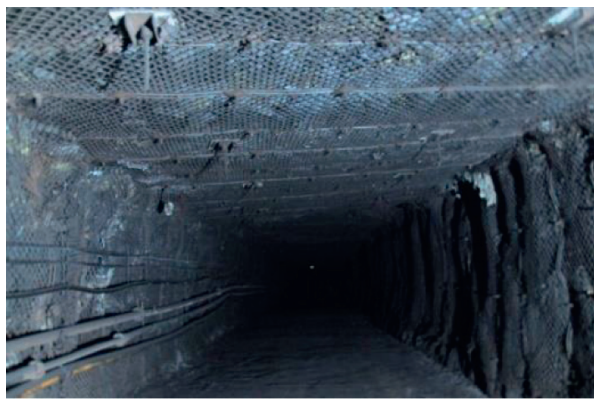

(a)

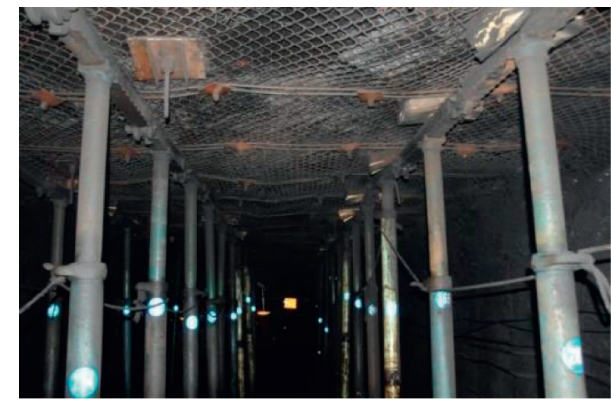

(b)

FIgURE 15: Deformation of roadway surrounding rock. (a) Roadway excavation; (b) working face mining.

\section{Conclusion}

(1) The catastrophe characteristics of surrounding rock of the large section roadway in the fault structure area are summarized. Based on the theory of damage mechanics, the tensile failure of the anchorage end in the middle of the roadway roof is proposed as the discrimination basis of the LSRTC. Taking the transportation roadway of 7105 working face of Wangzhuang Coal Mine as an example, an example study is carried out, which provides an important basis for the control of the surrounding rock of the large section roadway.

(2) The concept of size effect affecting the stability of the LSRTC is put forward, and the action mechanism of size effect inducing the LSRTC catastrophe is revealed: in the size effect, the deformation inflection point of roadway width factor is $4.5 \mathrm{~m}$, and the failure form of roadway roof is most significantly affected by the roadway width. There is no obvious inflection point in the deformation effect of roadway height factor in size effect, but the inflection point of damage effect of roadway height factor in size effect is $3.0 \mathrm{~m}$.

(3) The concept of tectonic stress intensity effect affecting the stability of the LSRTC is proposed, and the action mechanism of tectonic stress intensity effect inducing surrounding rock catastrophe of the LSRTC is studied: with the increase of lateral pressure coefficient of horizontal stress, the displacement of roof and floor increases linearly, and there is an inflection point between the two sides; that is, the lateral pressure coefficient of horizontal stress is 1.6.

(4) The surrounding rock control principle of the LSRTC based on the basic idea of "stabilizing top 
coal, reconstructing the coal wall and limiting floor heave" is proposed. The roadway surrounding rock stability control countermeasures with the core technology of "strong support roof + grouting reinforcement two sides + bolt barrier floor corner" are developed. On this basis, the industrial test is successfully carried out.

\section{Data Availability}

The data used to support the findings of this study are available from the corresponding authors.

\section{Conflicts of Interest}

The authors declare no conflicts of interest.

\section{Authors' Contributions}

Dingchao CHEN and Jianfei LU conceived and designed the research; Xiangqian ZHAO performed the numerical simulation and field tests; Yuxin PAN and Cheng CHEN provided theoretical guidance in the research process; Yang YU analyzed the data and wrote the paper.

\section{Acknowledgments}

This work was supported by the National Natural Science Foundation of China (grant nos. 51904296 and 52074240), the Outstanding Backbone Teachers of "Innovation Project" of University in Jiangsu Province, China, in 2020, Young academic leaders of "Innovation Project" of University in Jiangsu Province, China, in 2021, and Major Projects of Natural Science Foundation of Universities in Jiangsu Province, China (grant no. 20KJA560001). The sources of this support are gratefully acknowledged.

\section{References}

[1] H. Bloch, S. Rafiq, and R. Salim, "Economic growth with coal, oil and renewable energy consumption in China: prospects for fuel substitution," Economic Modelling, vol. 44, pp. 104-115, 2015.

[2] T. Thielemann, S. Schmidt, and J. Peter Gerling, "Lignite and hard coal: energy suppliers for world needs until the year 2100 - an outlook," International Journal of Coal Geology, vol. 72, no. 1, pp. 1-14, 2007.

[3] K. Xiao, F. Li, C. W. Dong et al., "Unraveling effects of coal output cut policy on air pollution abatement in China using a CGE model," Journal of Cleaner Production, vol. 269, p. 10, 2020.

[4] Y. Yu, L. Y. Zhang, J. F. Lu, D. C. Chen, X. Q. Zhao, and L. M. Liu, "Research on the evolution characteristics of floor stress and reasonable layout of roadways in deep coal mining," Geofluids, vol. 2021, Article ID 6631444, 17 pages, 2021.

[5] L. C. Cheng, J. Xu, and T. K. Lu, "Effects of tectonic stress on stability of dilatancy characteristic soft rock roadway intersection in deep underground," Disaster $A d v$, vol. 5, no. 4, pp. 1190-1195, 2012.

[6] S. T. Gu, B. Y. Jiang, G. S. Wang, H. B. Dai, and M. P. Zhang, "Occurrence mechanism of roof-fall accidents in large-section coal seam roadways and related support design for bayangaole coal mine, China," Advances in Civil Engineering, vol. 2018, Article ID 6831731, 17 pages, 2018.

[7] Y. Hao, Y. Wu, Y. L. Chen, P. Li, L. Chen, and K. Zhang, "An innovative equivalent width supporting technology for sustaining large-cross section roadway in thick coal seam," Arab J Geosci, vol. 12, no. 22, p. 12, 2019.

[8] W.-q. Peng, H. Zhu, Q. Wang, and G. Peng, "Study on safety control of large-section roadway with high stress and broken surrounding rock," Advances in Civil Engineering, vol. 2021, Article ID 6686208, 12 pages, 2021.

[9] Y. Tai, H. Xia, X. Meng, and T. Kuang, "Failure mechanism of the large-section roadway under mined zones in the ultrathick coal seam and its control technology," Energy Science \& Engineering, vol. 8, no. 4, pp. 999-1014, 2020.

[10] H. Wang, D. Wang, W. Ren, X. Lu, F. Han, and Y. Zhang, "Application of foam to suppress rock dust in a large crosssection rock roadway driven with roadheader," Advanced Powder Technology, vol. 24, no. 1, pp. 257-262, 2013.

[11] G. Z. Xue, C. Gu, X. Q. Fang, and T. Wei, “A case study on large deformation failure mechanism and control techniques for soft rock roadways in tectonic stress areas," Sustainability, vol. 11, no. 13, p. 24, 2019.

[12] Y. L. Yang, X. B. Li, and P. F. Li, "Study on surrounding rock deformation mechanism and control of roadway with large section and extra-thick top coal," Shock and Vibration, vol. 2021, Article ID 6618424, 11 pages, 2021.

[13] J. D. Yin, B. J. Fu, and H. L. Zhang, "Failure mechanism and control technology for a large-section roadway under weakly cemented formation condition," Geofluids, vol. 2020, Article ID 6669060, 11 pages, 2020.

[14] S. Zhang, D. Zhang, H. Wang, and S. Liang, "Discrete element simulation of the control technology of large section roadway along a fault to drivage under strong mining," Journal of Geophysics and Engineering, vol. 15, no. 6, pp. 2642-2657, 2018.

[15] Y. M. Zhao, "Study on the support technology of large section roadway in soft rock stratum of high-stress fracture zones," Basic and Clinical Pharmacology and Toxicology, vol. 127, p. 223, 2020.

[16] X. G. Ma, M. C. He, J. Wang, Y. B. Gao, D. Y. Zhu, and Y. X. Liu, "Mine strata pressure characteristics and mechanisms in gob-side entry retention by roof cutting under medium-thick coal seam and compound roof conditions," Energies, vol. 11, no. 10, p. 25, 2018.

[17] Y. Yu, X. Y. Wang, J. B. Bai, L. Y. Zhang, and H. C. Xia, "Deformation mechanism and stability control of roadway surrounding rock with compound roof: research and applications," Energies, vol. 13, no. 6, p. 19, 2020.

[18] M. R. Islam and R. Shinjo, "Numerical simulation of stress distributions and displacements around an entry roadway with igneous intrusion and potential sources of seam gas emission of the Barapukuria coal mine, NW Bangladesh," International Journal of Coal Geology, vol. 78, no. 4, pp. 249-262, 2009.

[19] Q.-r. Kang, J.-X. Tang, H. Hu, and W.-z. Zhang, "Stress distribution rule of roadway affected by overhead mining in gently inclined coal seams group," Transactions of Nonferrous Metals Society of China, vol. 21, pp. S529-S535, 2011.

[20] X. Y. Wang, G. H. Wang, B. W. Wu, and S. G. Liu, "Study on the lagging support mechanism of anchor cable in coal roadway based on FLAC(3D) modified model," Advances in Civil Engineering, vol. 2021, Article ID 9919454, 12 pages, 2021. 
[21] Q. S. Bai and S. H. Tu, "Numerical observations of the failure of a laminated and jointed roof and the effective of different support schemes: a case study," Environ Earth Sci, vol. 79, no. $10,2020$.

[22] W. Zhang, J. J. Tang, D. S. Zhang, L. Zhang, Y. Y. Sun, and W. S. Zhang, "Experimental study ON the joint application $\mathrm{OF}$ innovative techniques for the improved drivage $\mathrm{OF}$ roadways at depths over $1 \mathrm{KM}$ : a case study," Archives of Mining Sciences, vol. 65, no. 1, pp. 159-178, 2020.

[23] Z. Z. Zhang, M. Deng, X. Y. Wang, W. J. Yu, F. Zhang, and V. D. Dao, "Field and numerical investigations on the lower coal seam entry failure analysis under the remnant pillar," Engineering Failure Analysis, vol. 115, 2020.

[24] Z. Z. Zhang, J. L. Xin, J. B. Bai, X. Y. Yu, W. J. Yu, and M. Deng, "Determination of cyclic filling length in gob-side entry retained with roadside filling and its application," Shock and Vibration, vol. 2021, Article ID 4055358, 16 pages, 2021.

[25] X. D. Zhao, H. B. Li, S. J. Zhang, and X. M. Yang, "Stability analyses and cable bolt support design for A deep large-span stope at the hongtoushan mine, China," Sustainability, vol. 11, no. $21,2019$. 